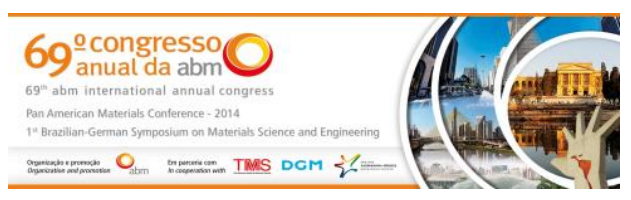

Tema:Iniciação científico-tecnológica

\title{
ANÁLISE DO COMPORTAMENTO DO FLUIDO DE CORTE INTEGRAL COMERCIAL COMPARATIVAMENTE COM FORMULAÇÕES BIODEGRADÁVEIS NO PROCESSO DE RETIFICAÇÃ̃O*
}

\author{
Cintia Braga ${ }^{1}$ \\ Leonardo Roberto da Silva² \\ Evanilton José Alves Barbosa ${ }^{3}$ \\ Izabela Silva Bicalho' \\ Felipe Amaral Oliveira ${ }^{1}$ \\ Helane Lúcia Oliveira de Morais ${ }^{3}$ \\ Claudinei Rezende Calado 4 \\ Elaine Carballo Siqueira Corrêa ${ }^{5}$
}

\section{Resumo}

O processo de retificação é empregado na fabricação de componentes que requerem excelente qualidade dimensional com elevado acabamento superficial. $O$ desempenho deste processo depende muito das condições de lubri-refrigeração produzidas pelos fluidos de corte, que são utilizados para amenizar os problemas que afetam a integridade superficial das peças, como queima e danos microestruturais, e também proporcionar melhor desempenho do processo e aumento da vida útil do rebolo. Entretanto, os fluidos de corte são uma das fontes mais problemáticas na manufatura, pois são produtos nocivos ao meio ambiente e a saúde humana, e aparecem como elemento determinante para a otimização do processo de fabricação. Desta maneira, este projeto visa analisar o comportamento do fluido de corte integral comercial em comparação com formulações biodegradáveis (óleos de soja e milho) no processo de retificação cilíndrica externa de mergulho no aço ABNT 4340 temperado e revenido com dureza média de 52 HRc. A avaliação do desempenho dos fluidos consistiu na análise da integridade superficial (rugosidade, microestrutura e microdureza) e no desgaste do rebolo. Os resultados comprovaram a eficiência dos óleos vegetais e viabilidade do uso no processo de retificação, proporcionando melhoria na eficiência do processo e contribuindo para uma manufatura ecologicamente correta.

Palavras-chave:Fluido de corte; Processo de retificação; Integridade superficial; Óleos vegetais.

\section{ANALYSIS OF THE BEHAVIOR OF MINERAL BASED COMMERCIAL CUTTING FLUID COMPARED WITH BIODEGRADABLE FORMULATIONS IN GRINDING PROCESS}

\section{Abstract}

The grinding process is used to manufacture components requiring excellent dimensional precision with high quality surface finish. The performance of this process depends heavily on the lubrication and cooling conditions produced by cutting fluids, which are used to reduce the problems that affect surface integrity of the parts, such as burning and microstructural damage, and also provide better process performance and an increased useful life of the grindstone. However, cutting fluids are one of the most problematic sources in manufacturing. They are harmful to the environment and human health and appear as a crucial element to the optimization of manufacturing process. Thus, this project aims to analyze the behavior of the mineral based commercial cutting fluid compared with biodegradable formulations (soybean and corn oils) on the external cylindrical plunge grinding on AISI 4340 steel quenched and tempered with hardness of $52 \mathrm{HRc}$. Performance evaluation of fluids consisted in the analysis of surface integrity (roughness, microstructure and microhardness) and wheel wear. The results have proved the efficiency of vegetable oils and feasibility of use in the grinding process, providing improvement in the efficiency of the process and contributing to an environmentally friendly manufacturing.

Keywords: Cutting fluid; Grinding process; Surface integrity; Vegetable oils.

1 Engenharia de Materiais, Graduando, Departamento de Engenharia de Materiais, CEFET-MG, Belo Horizonte, Minas Gerais, Brasil.

2 Engenharia Mecânica, Doutor, Professor, Departamento de Engenharia de Materiais, CEFET-MG, Belo Horizonte, Minas Gerais, Brasil.

3 Engenharia de Materiais, Mestrando, Departamento de Engenharia de Materiais, CEFET-MG, Belo Horizonte, Minas Gerais, Brasil.

4 Química, Doutor, Professor, Departamento de Química, CEFET-MG, Belo Horizonte, Minas Gerais, Brasil.

5 Engenharia Mecânica, Doutora, Professora, Departamento de Engenharia de Materiais, CEFET-MG, Belo Horizonte, Minas Gerais, Brasil.

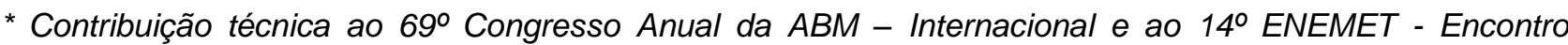
Nacional de Estudantes de Engenharia Metalúrgica, de Materiais e de Minas,21 a 25 de julho de 2014, São Paulo, SP, Brasil.
} 


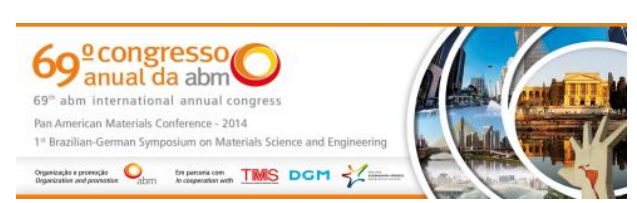

\section{INTRODUÇÃO}

A retificação é um processo de usinagem de geometria não definida no qual ocorre a interação entre os grãos abrasivos da ferramenta (rebolo) e a peça a ser retificada. É utilizado para a obtenção de peças com tolerância dimensional rigorosa e baixa rugosidade. Por ser um processo que envolve elevadas temperaturas e alta velocidade de corte podem ocorrer danos térmicos e tensões residuais que afetam a integridade superficial do componente usinado [1].

Segundo Alves et al. [2], um dos danos mais comuns devido às elevadas temperaturas é a queima da peça. O início da queima superficial leva ao aumento da adesão de partículas metálicas no rebolo. Isso provoca a elevação das forças de retificação e, consequentemente, a perda de qualidade superficial do componente e a redução da vida útil do rebolo, que sofre maior desgaste.

Com o objetivo de reduzir os danos térmicos e os problemas que afetam a qualidade superficial das peças retificadas são empregados os fluidos de corte, cujo objetivo é a lubrificação e refrigeração, além de auxiliar na remoção dos cavacos [3]. Dessa forma tem-se a dissipação do calor gerado no processo e a redução do atrito na interface peça/rebolo, possibilitando a produção de peças dentro dos padrões desejados e um aumento na vida útil da ferramenta [4].

Os fluidos de corte, entretanto, possuem em sua composição elevado número de componentes tóxicos, sendo, portanto, agressivos ao meio ambiente a à saúde do operador. Devido a esses problemas existe uma tendência mundial de reduzir a utilização de óleos integrais utilizando como alternativa os fluidos de corte ambientalmente corretos, como os óleos de origem vegetal [5].

O objetivo deste trabalho é a comparação do comportamento do fluido de corte integral comercial com os óleos de origem vegetal de soja e de milho na retificação cilíndrica externa de mergulho do aço ABNT 4340, temperado e revenido, com dureza média de 52HRc. A análise do desempenho dos fluidos de corte foi feita através da avaliação da rugosidade, microestrutura e microdureza das peças retificadas e do desgaste diametral do rebolo.

\section{MATERIAIS E MÉTODOS}

Os ensaios foram realizados nos laboratórios de Retificação, de Metalografia e Microdureza e de Caracterização de Materiais do Departamento de Engenharia de Materiais do CEFET/MG.

\subsection{Ensaios de Retificação}

Os corpos de prova utilizados foram de aço ABNT 4340, temperado e revenido com dureza média de 52HRc.

$\mathrm{O}$ rebolo utilizado foi um rebolo convencional de óxido de alumínio $\left(\mathrm{Al}_{2} \mathrm{O}_{3}\right)$, com as seguintes dimensões e características: (355,6 x 50,8 x 127 mm - FE 38A60KV) onde durante a usinagem foi deixado aproximadamente $7,0 \mathrm{~mm}$ na largura do mesmo.

Os fluidos de corte utilizados na retificação foram o óleo mineral Mecafluid 14SC da marca Petronas Lubrificantes do Brasil de base parafínica contendo aditivos sulfoclorados inativos indicados para operações de corte em geral, e os óleos vegetais (soja-Glycinemax e milho-Zeamays) do fabricante Campestre, e utilizados sem nenhum tratamento adicional.

\footnotetext{
* Contribuição técnica ao $69^{\circ}$ Congresso Anual da ABM - Internacional e ao 14ํㅡㄹ ENEMET - Encontro Nacional de Estudantes de Engenharia Metalúrgica, de Materiais e de Minas,21 a 25 de julho de 2014, São Paulo, SP, Brasil.
} 


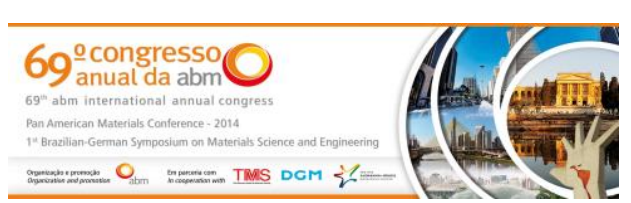

Os ensaios foram realizados em uma retificadora cilíndrica universal, marca TosHostivar, com potência equivalente a $9 \mathrm{~kW}$.

Os ensaios foram realizados em três condições de usinagem distintas, constituídas por ciclos de retificação. As especificações das condições de usinagem utilizadas são apresentadas na Tabela 1.

Tabela 1. Condições de usinagem utilizadas

\begin{tabular}{|c|c|c|c|}
\hline Parâmetros & Condição 1 & Condição 2 & Condição 3 \\
\hline $\begin{array}{l}\text { Velocidade de } \\
\text { mergulho }\end{array}$ & $1,2 \mathrm{~mm} / \mathrm{min}$ & $0,8 \mathrm{~mm} / \mathrm{min}$ & $1,2 \mathrm{~mm} / \mathrm{min}$ \\
\hline $\begin{array}{l}\text { Tempo de } \\
\text { spark out }\end{array}$ & 10 segundos & 10 segundos & 5 segundos \\
\hline Número de ciclos & 6 & 9 & 36 \\
\hline $\begin{array}{l}\text { Tempo de cada } \\
\text { ciclo }\end{array}$ & 60 segundos & 60 segundos & 10 segundos \\
\hline Sobre metal & $\begin{array}{c}1,2 \mathrm{~mm} \text { ao final de } \\
\text { cada ciclo }\end{array}$ & $\begin{array}{c}0,8 \mathrm{~mm} \text { ao final de } \\
\text { cada ciclo }\end{array}$ & $\begin{array}{l}0,2 \mathrm{~mm} \text { ao final de } \\
\text { cada ciclo }\end{array}$ \\
\hline
\end{tabular}

O sobre metal de $0,2 \mathrm{~mm}$ foi escolhido devido às condições de utilização no meio industrial, fazendo-se uma simulação do processo de fabricação. Dessa maneira em todas as condições de usinagem foi possível obter uma redução de $7,2 \mathrm{~mm}$ no diâmetro do corpo de prova. Para cada fluido de corte foram retificados 6 corpos de prova em cada uma das 3 condições de usinagem, totalizando 54 peças usinadas.

\subsection{Medição de Rugosidade e Desgaste do Rebolo}

Para a medição de rugosidade os corpos de prova foram previamente limpos com o auxílio de álcool e algodão e preparados em uma superfície de apoio para facilitar a utilização do apalpador. A rugosidade foi definida pelo parâmetro de amplitude $\mathrm{Ra}$ de acordo com a norma JIS B 0601-2001 [6], e o comprimento de medição "cut-off" utilizado foi de $0,8 \mathrm{~mm}$. As medições foram feitas com um rugosímetro Mitutoyo, modelo SJ-301.

A rugosidade foi medida em quatro posições radiais e equidistantes a $90^{\circ}$ aproximadamente. Posteriormente foram calculados a média e o desvio padrão dos resultados obtidos.

Durante a retificação, o rebolo estava posicionado de maneira que uma de suas extremidades não executava corte e não sofria desgaste. Após a retificação de 3 peças, foi utilizado um corpo de prova cilíndrico retificado de aço ABNT 1020 que foi colocado na retificadora para obter a marcação do perfil desgastado do rebolo. A Figura 1 mostra a realização da impressão do desgaste no corpo de prova.

\footnotetext{
* Contribuição técnica ao $69^{\circ}$ Congresso Anual da ABM - Internacional e ao 14ํㅡㄹ ENEMET - Encontro Nacional de Estudantes de Engenharia Metalúrgica, de Materiais e de Minas,21 a 25 de julho de 2014, São Paulo, SP, Brasil.
} 

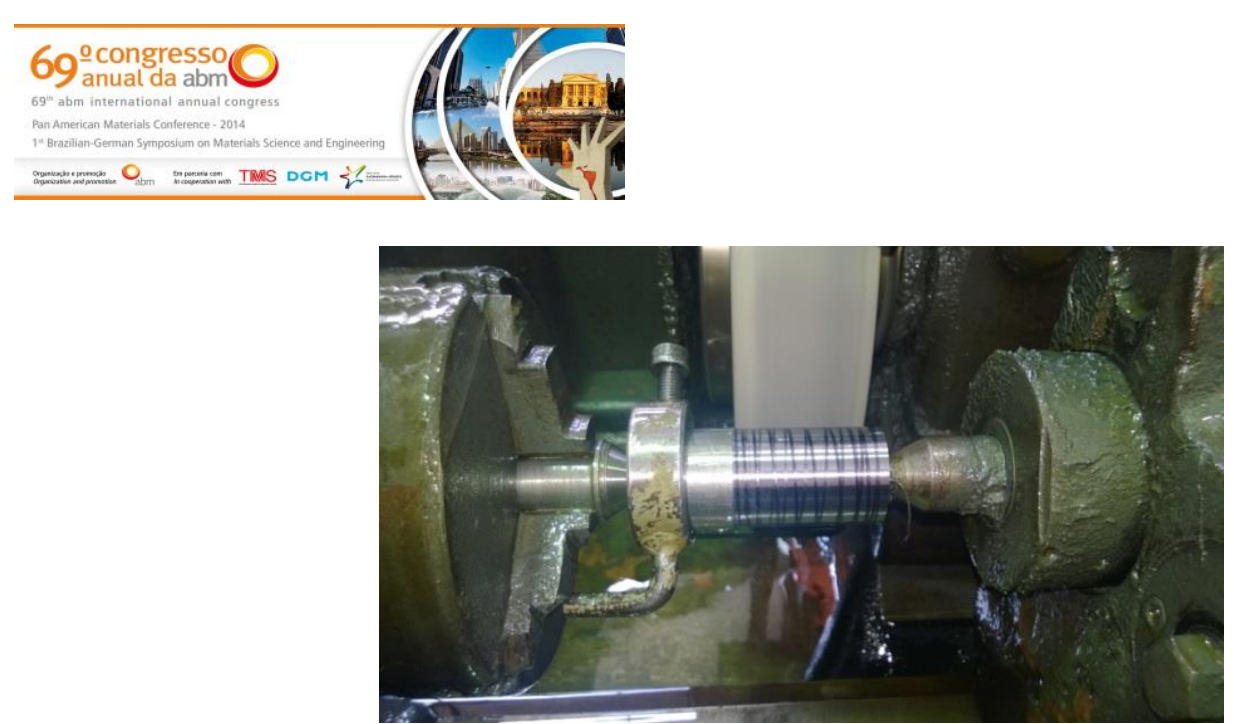

Figura 1. Impressão do desgaste do rebolo em corpo de prova de aço ABNT 1020.

O desgaste foi medido utilizando o parâmetro $\mathrm{Pt}$, que é uma representação do desnível entre planos. Foram realizadas quatro medições de modo semelhante à medição de rugosidade das peças. Posteriormente foram calculados a média e o desvio padrão dos valores obtidos e, finalmente, a média e o desvio padrão finais.

\subsection{Ensaio de Microdureza}

A microdureza das peças retificadas foi avaliada com o auxílio do Microdurômetro Vickers da marca Shimadzu, modelo HMV2, seguindo a norma ASTM E-384-99 [7].

As amostras foram lixadas em lixas de granulometrias 400 e 600 e posteriormente polidas em uma máquina politriz com pasta de diamante para polimento metalográfico com tamanhos de partículas $3 \mu \mathrm{m}$ e $9 \mu \mathrm{m}$. Após o polimento a superfície das amostras apresentavam um plano com comprimento entre $3,5 \mathrm{~mm}$ a $4,5 \mathrm{~mm}$.

A carga aplicada em cada teste foi de 300gf por um período de $15 \mathrm{~s}$. Durante os ensaios foram realizadas 10 medições em duas regiões distintas da amostras, de forma a obter valores de microdureza em diferentes profundidades na sub-superfície da peça. A primeira linha de identação foi feita com uma distância de 2,0mm de uma das extremidades da amostra e a segunda com a mesma distância da outra extremidade. As dez identações em cada linha foram feitas com uma distância de $0,1 \mathrm{~mm}$ entre uma e outra e $0,1 \mathrm{~mm}$ da borda do plano criado no polimento, conforme mostra o esquema da Figura 2.
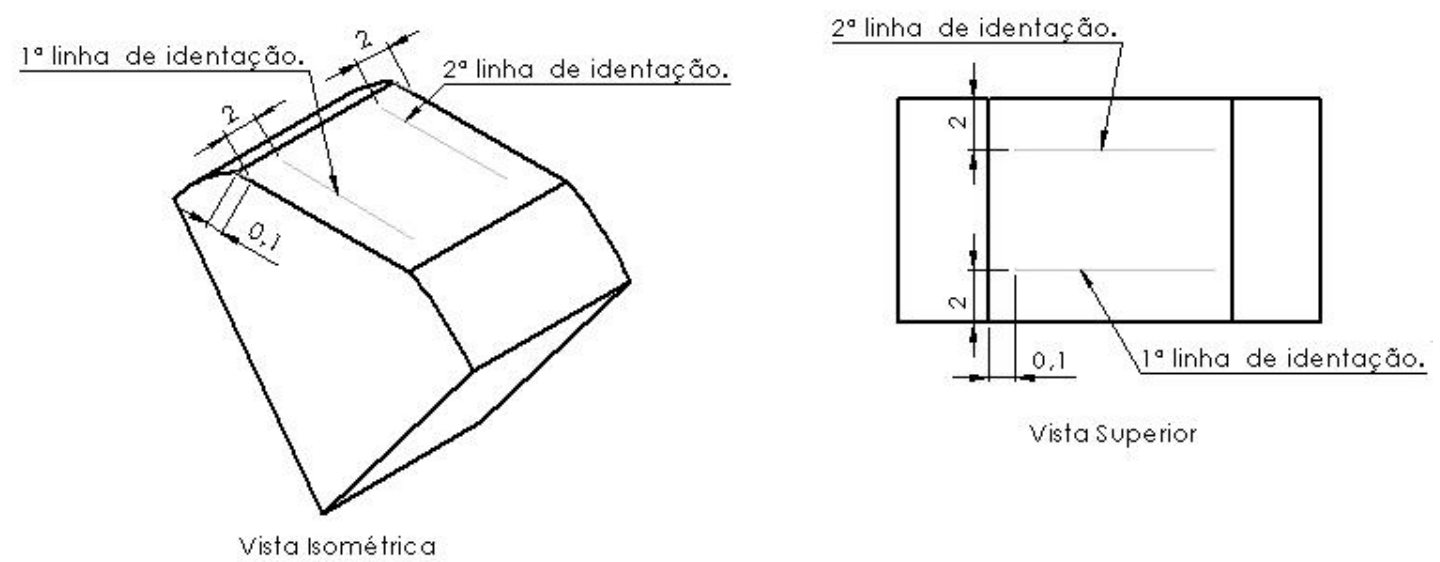

Figura 2. Padronização da medição de microdureza.

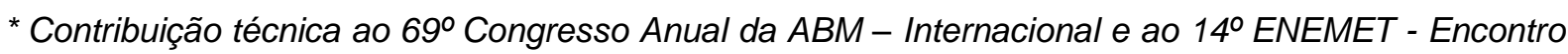
Nacional de Estudantes de Engenharia Metalúrgica, de Materiais e de Minas,21 a 25 de julho de 2014, São Paulo, SP, Brasil.
} 


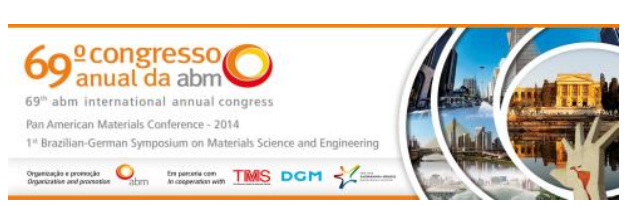

A Figura 3 mostra a vista lateral do plano feito no polimento.

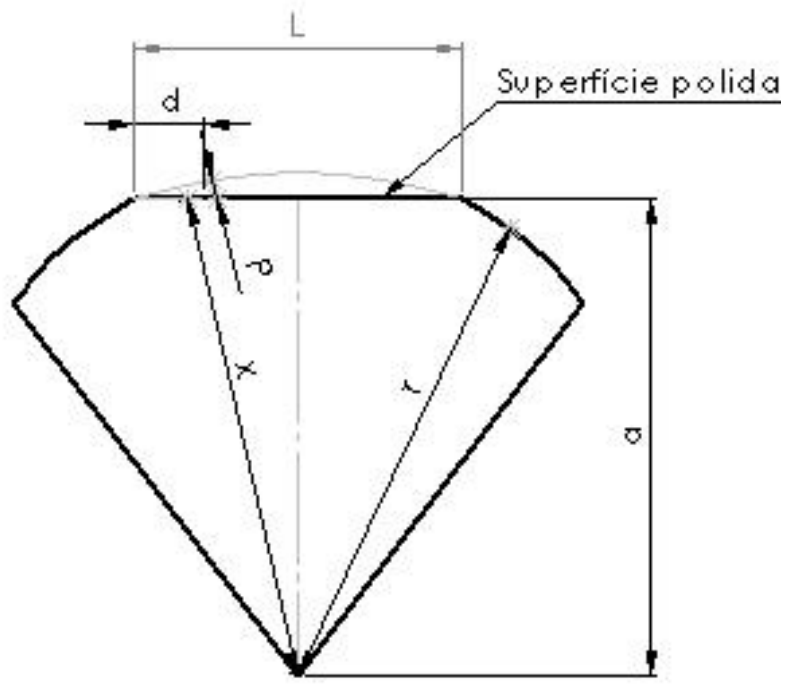

Figura 3. Vista lateral da amostra: Relações geométricas para o cálculo da profundidade.

Na Figura 3, p é a profundidade e d é a distância entre a identação e a borda do plano.

Pelo Teorema de Pitágoras, tem-se (Equação 1):

$$
x^{2}=\left(a^{2}+(L / 2-d)^{2}\right.
$$

Observando a figura, tem-se que (Equação 2):

$$
p=R-x
$$

Através dessas das Equações 1 e 2, e considerando o valor do raio das peças padronizado como $15 \mathrm{~mm}$ e o plano criado com comprimento de $4 \mathrm{~mm}$, foi possível calcular a profundidade (distância da superfície original) onde foi realizada cada medição. O valor da profundidade das medições variou de 13,0 $\mu \mathrm{m}$ a 100,3 $\mu \mathrm{m}$.

Considerando a retificação feita com cada óleo, foi escolhido, para cada condição de usinagem, o corpo de prova que apresentou valor de rugosidade mais próximo da média. Ou seja, do total de 54 corpos de prova usinados, foram preparadas 9 amostras para os ensaios de microdureza. Além disto, ainda foi submetida à medição da microdureza uma amostra não retificada, para melhor comparação dos resultados. No total,a medição de microdureza foram feitas em 10 amostras.

\subsection{Análise microestrutural - Microscopia eletrônica de varredura (MEV)}

Com o objetivo de verificar os possíveis danos na superfície do material causados pelas solicitações térmicas e mecânicas ocorridas para cada condição de lubrirefrigeração investigada, (fluidos de corte integral, óleo de soja e óleo de milho), foi feita uma análise microestrutural utilizando microscopia eletrônica de varredura.

Os mesmos corpos de prova escolhidos para os ensaios de microdureza foram cortados para a obtenção de amostras a serem preparadas para a análise microestrutural, totalizando 10 amostras analisadas.

\footnotetext{
* Contribuição técnica ao $69^{\circ}$ Congresso Anual da ABM - Internacional e ao 14ํㅡㄹ ENEMET - Encontro Nacional de Estudantes de Engenharia Metalúrgica, de Materiais e de Minas,21 a 25 de julho de 2014, São Paulo, SP, Brasil.
} 


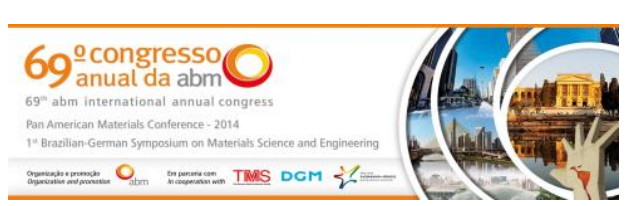

As amostras foram submetidas a procedimentos metalográficos, embutidas, lixadas com lixas de diferentes granulometrias (220, 320, 400 e 600), polidas em uma máquina politriz com pasta de diamante para polimento metalográfico com tamanhos de partículas de $3 \mu \mathrm{m}$ e $9 \mu \mathrm{m}$. Todas as amostras foram atacadas quimicamente utilizando Nital 3\%.

Foi utilizado um microscópio eletrônico de varredura da marca Shimadzu, modelo SSX 550, Superscan, onde foram realizadas ampliações de 1000 vezes.

\section{RESULTADOS E DISCUSSÃO}

\subsection{Rugosidade}

Os valores médios de rugosidade, avaliada pelo parâmetro $\mathrm{Ra}$, são apresentados nos gráficos de barras das Figuras 4 a 6 .

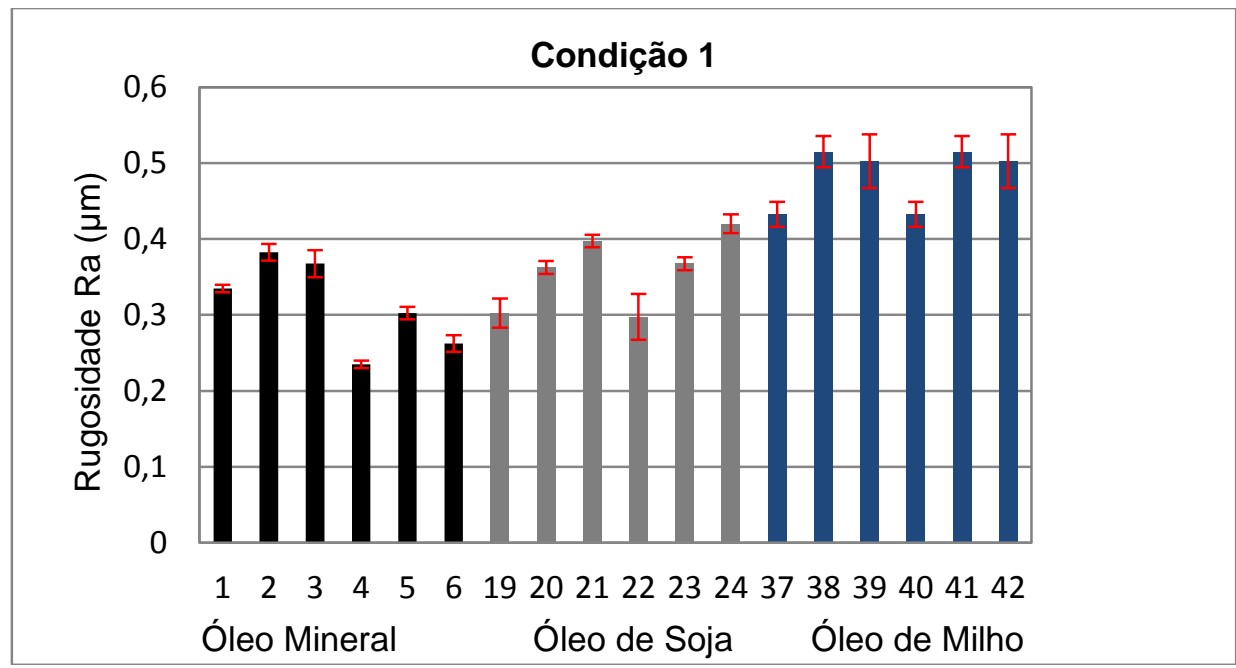

Figura 4. Rugosidade dos corpos de prova retificados com os óleos integral, de soja e de milho na condição de usinagem 1.

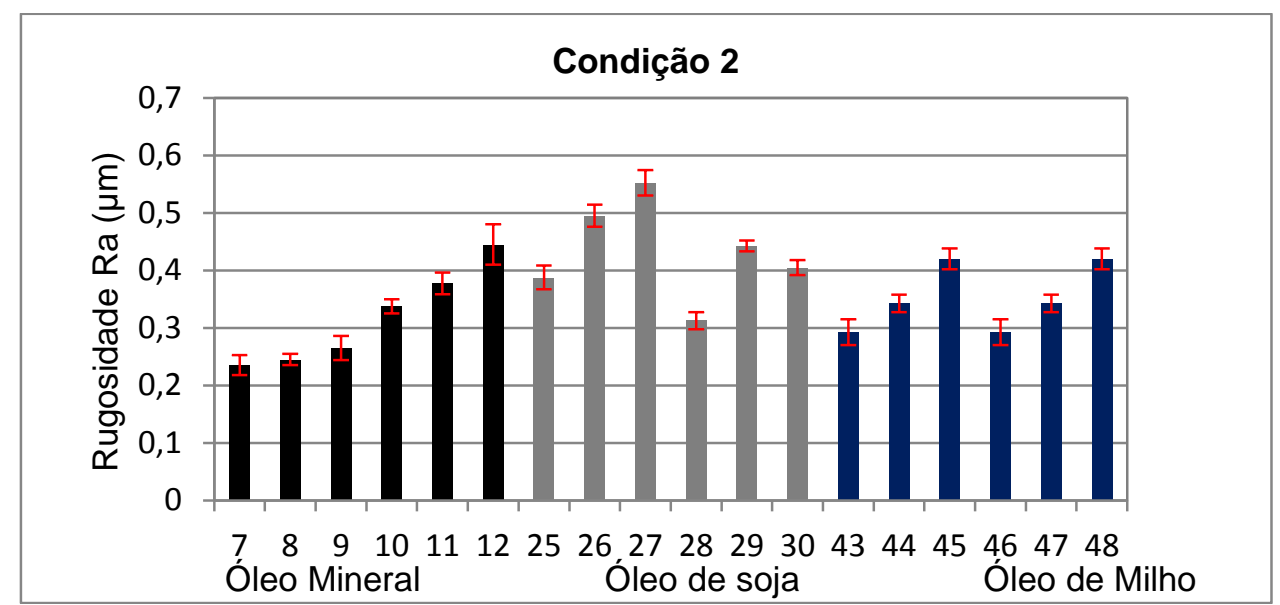

Figura 5. Rugosidade dos corpos de prova retificados com os óleos integral, de soja e de milho na condição de usinagem 2.

\footnotetext{
* Contribuição técnica ao $69^{\circ}$ Congresso Anual da ABM - Internacional e ao 14ํㅡㄹ ENEMET - Encontro Nacional de Estudantes de Engenharia Metalúrgica, de Materiais e de Minas,21 a 25 de julho de 2014, São Paulo, SP, Brasil.
} 

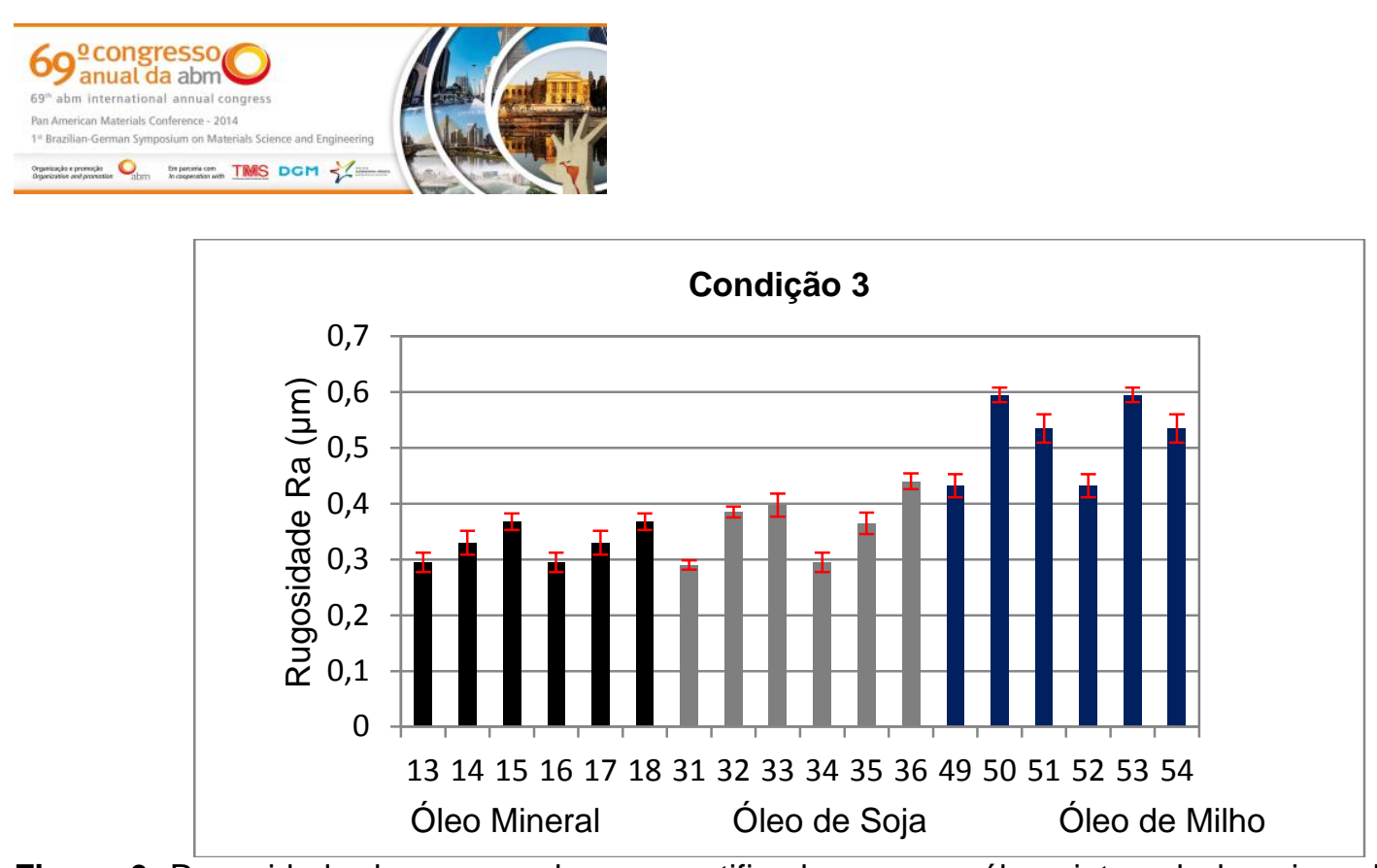

Figura 6. Rugosidade dos corpos de prova retificados com os óleos integral, de soja e de milho na condição de usinagem 3.

Observando os gráficos percebe-se que os valores de rugosidade, considerando as três condições de usinagem, foram próximos para retificação com os óleos mineral e de soja. Os valores de rugosidade mais baixos foram observados na condição 2, na qual a velocidade de corte era menor. Os corpos de prova retificados com óleo de milho foram os que apresentaram maiores valores de rugosidade, entretanto, na condição de usinagem 2, os valores de rugosidade na retificação com óleo de milho foram próximos aos demais.

A menor variação dos resultados, considerando as três condições de usinagem, foi obtida com o óleo de milho. E em uma análise de todos os fluidos, a menor variação foi observada na condição de usinagem 3 . A menor variação observada corresponde a uma superfície mais uniforme, aspecto importante para as operações de retificação.

\subsection{Desgaste Diametral do Rebolo}

As Figuras 7 a 9 apresentam os dados relativos ao desgaste do rebolo em função das diferentes condições de usinagem e lubri-refrigeração.

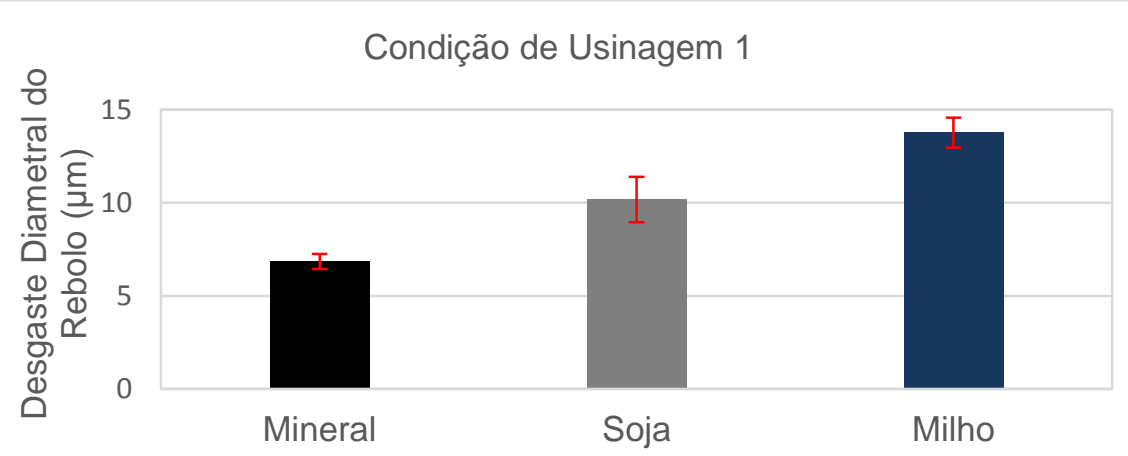

Figura 7. Desgaste diametral de rebolo obtidos após retificação na condição de usinagem 1 para os diferentes fluidos.

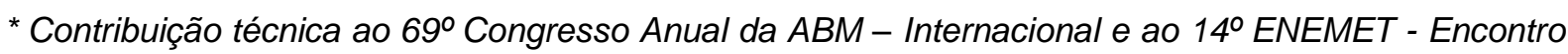
Nacional de Estudantes de Engenharia Metalúrgica, de Materiais e de Minas,21 a 25 de julho de 2014, São Paulo, SP, Brasil.
} 

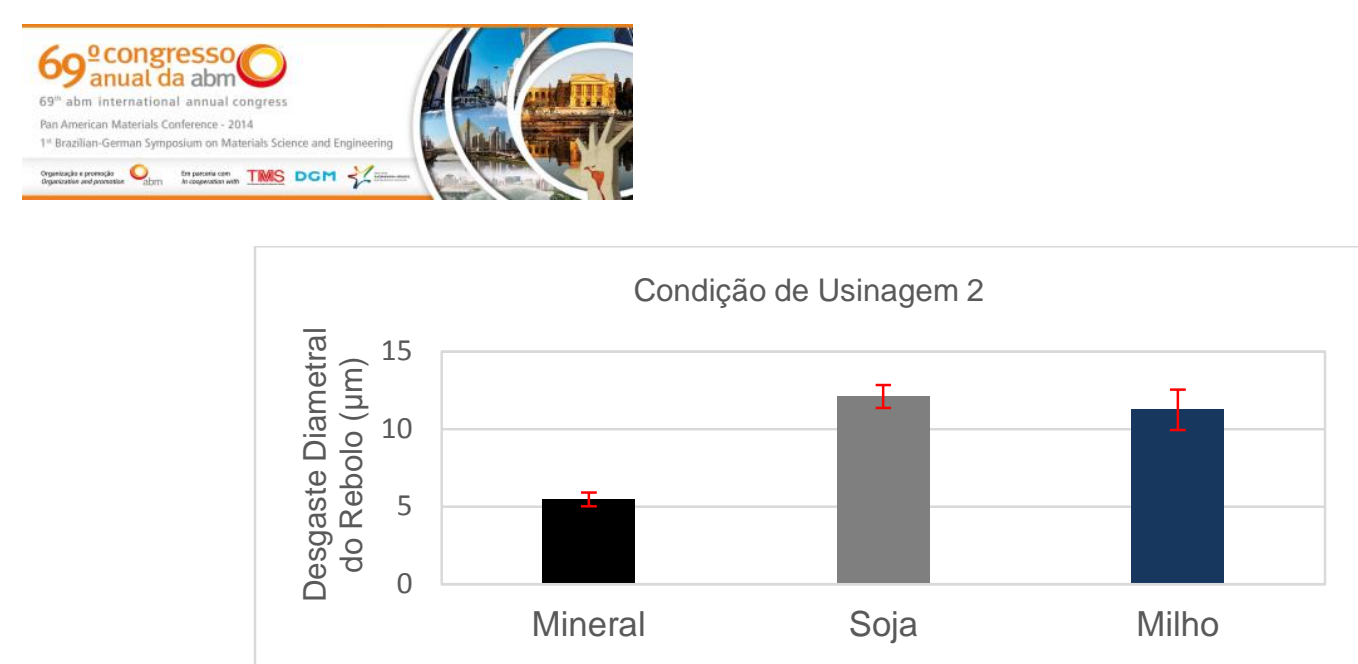

Figura 8. Desgaste diametral de rebolo após retificação na condição de usinagem 2 para os diferentes fluidos.

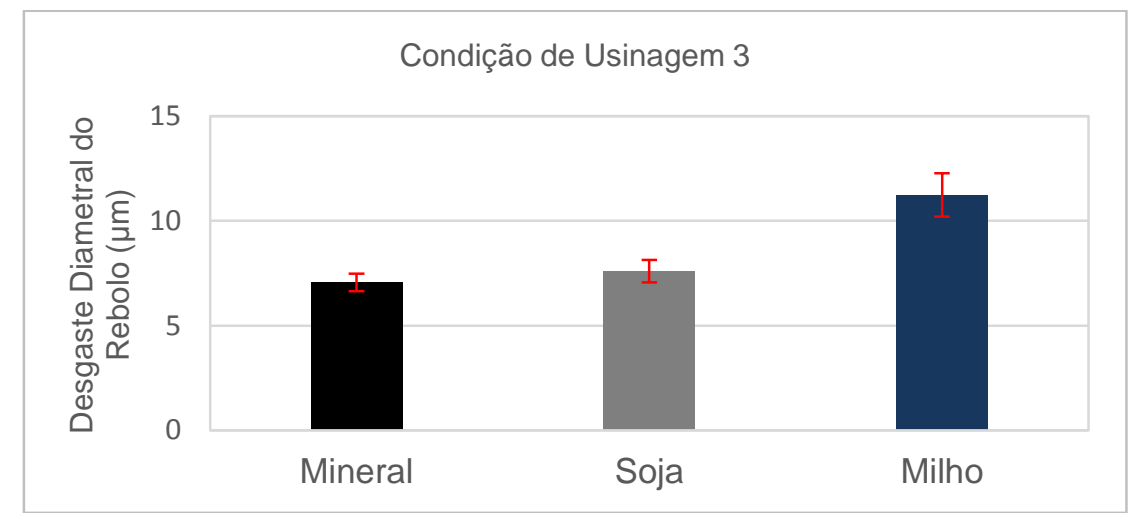

Figura 9. Desgaste diametral de rebolo após retificação na condição de usinagem 3 para os diferentes.

Analisando o gráfico percebe-se que nas condições de usinagem 1 e 2 as diferentes condições de lubri-refrigeração levaram a resultados distintos em termos de desgaste do rebolo. Nas duas condições o óleo mineral foi o que levou ao menor desgaste.

$\mathrm{Na}$ condição de usinagem 3, que simula condições industriais, o desgaste diametral do rebolo na retificação com óleo de milho foi elevado, porém, os valores de desgaste foram muito próximos considerando os óleos mineral e de soja.

\subsection{Análise Microestrutural}

As Figuras 10 a 12 representam as microestruturas das amostras analisadas por meio da microscopia eletrônica de varredura, com o intuito de verificar possíveis danos causados na sub-superfície do material por meio das solicitações térmicas e mecânicas as quais foram submetidas.

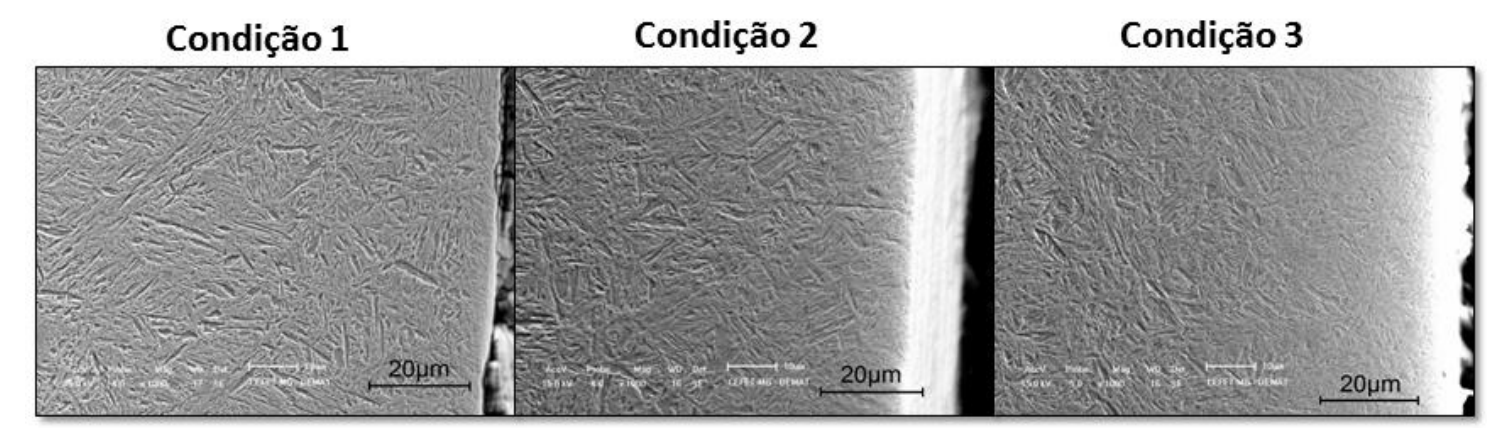

Figura 10. Micrografias da sub-superfície de amostras retificadas com óleo mineral nas condições de usinagem 1,2 e 3 (1.000X).

\footnotetext{
* Contribuição técnica ao $69^{\circ}$ Congresso Anual da ABM - Internacional e ao 14ํㅡㄹ ENEMET - Encontro Nacional de Estudantes de Engenharia Metalúrgica, de Materiais e de Minas,21 a 25 de julho de 2014, São Paulo, SP, Brasil.
} 


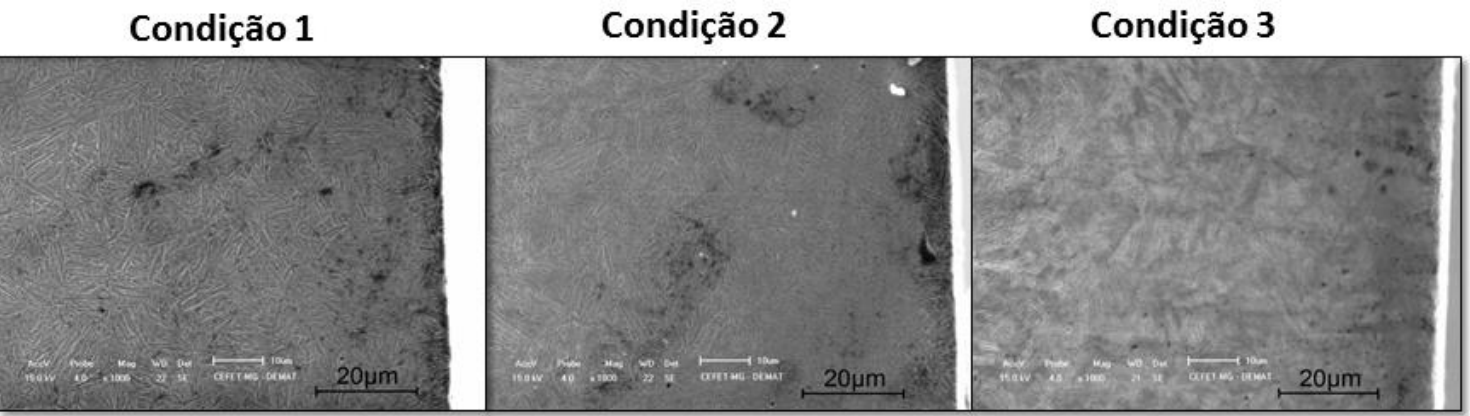

Figura 11. Micrografias da sub-superfície de amostras retificadas com óleo de soja nas condições de usinagem 1, 2 e 3 (1.000X).

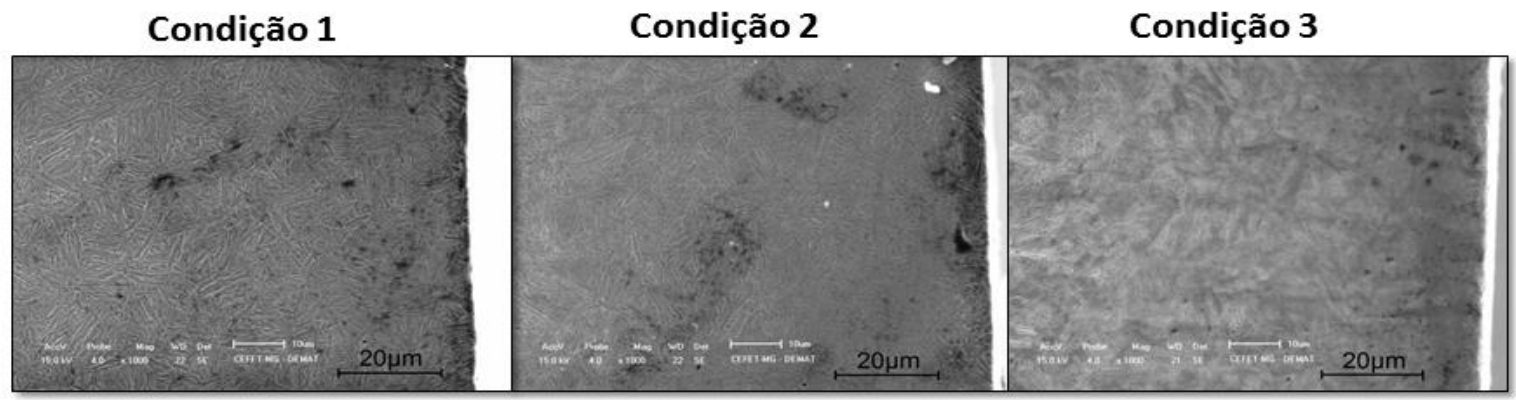

Figura 12. Micrografias da sub-superfície de amostras retificadas com óleo de milho nas condições de usinagem 1, 2 e 3 (1.000X).

A Figura 13 mostra a micrografia da sub-superfície da amostra sem retificação.

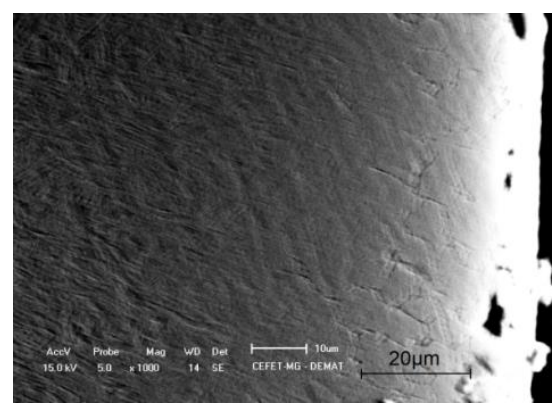

Figura 13. Micrografia obtida em MEV da sub-superfície de amostra não retificada (1.000X).

Observa-se a presença de martensita em todas as micrografias para todos os fluidos de corte. Fazendo uma comparação com a micrografia da amostra não-retificada é possível observar uma alteração microestrutural na sub-superfície das amostras retificadas, estas se apresentam com maior quantidade de martensita. A amostra não retificada apresenta ainda algumas trincas superficiais.

Os três fluidos de corte (óleos mineral, de soja e de milho) se comportaram de maneira eficaz uma vez que as alterações ocorridas na microestrutura já são esperadas para o processo de retificação e não levam ao comprometimento da integridade superficial das peças.

\subsection{Microdureza}

Os valores de microdureza encontrados estão associados à capacidade de dissipação de calor e velocidade de resfriamento dos corpos de prova, pois a temperatura e modo de resfriamento são fatores determinantes na definição da microestrutura obtida.

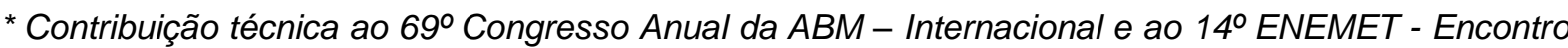
Nacional de Estudantes de Engenharia Metalúrgica, de Materiais e de Minas,21 a 25 de julho de 2014, São Paulo, SP, Brasil.
} 


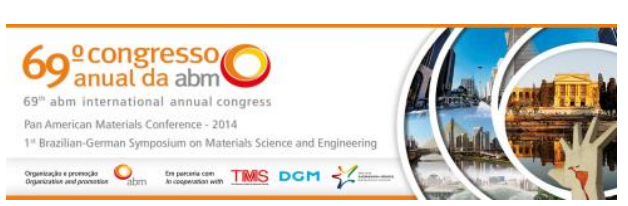

As Figuras 14 a 16 apresentam os valores de Microdureza x Profundidade para as três condições de usinagem utilizadas e para a amostra sem retificação.

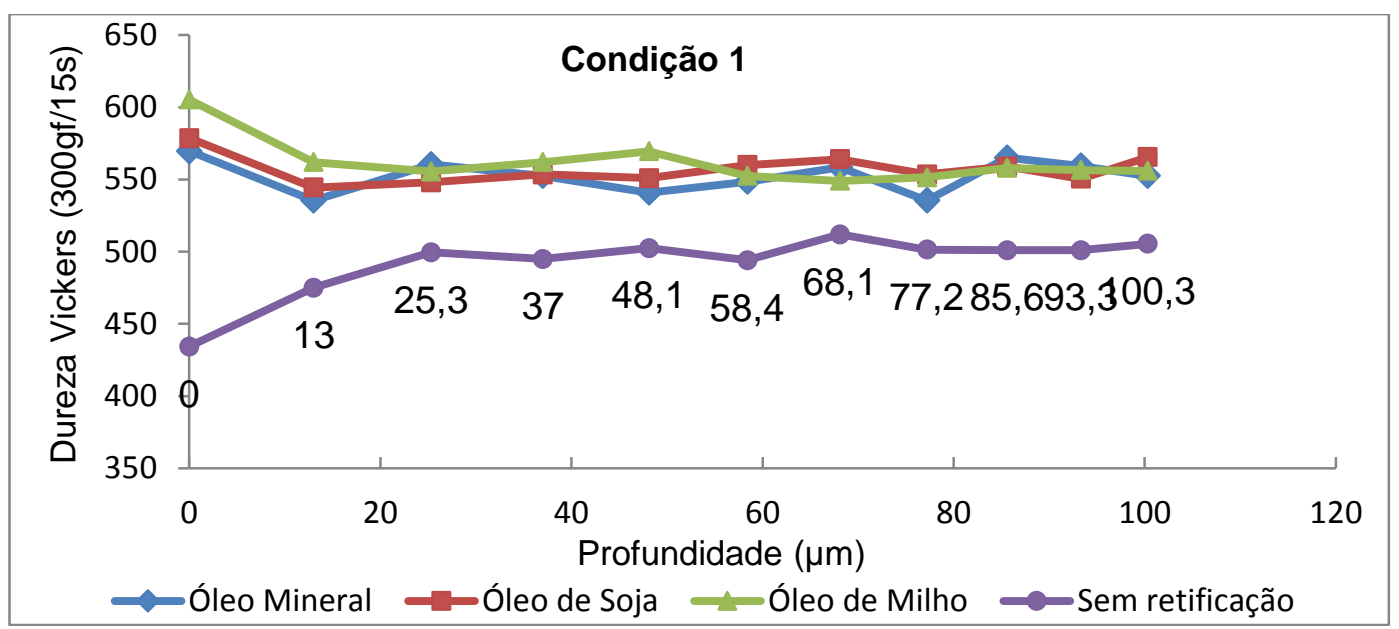

Figura 14. Valores de microdureza obtidos na condição de usinagem $1\left(V_{f}=1,2 \mathrm{~mm} / \mathrm{min}\right.$ e $\left.t_{s}=10 \mathrm{~s}\right)$.

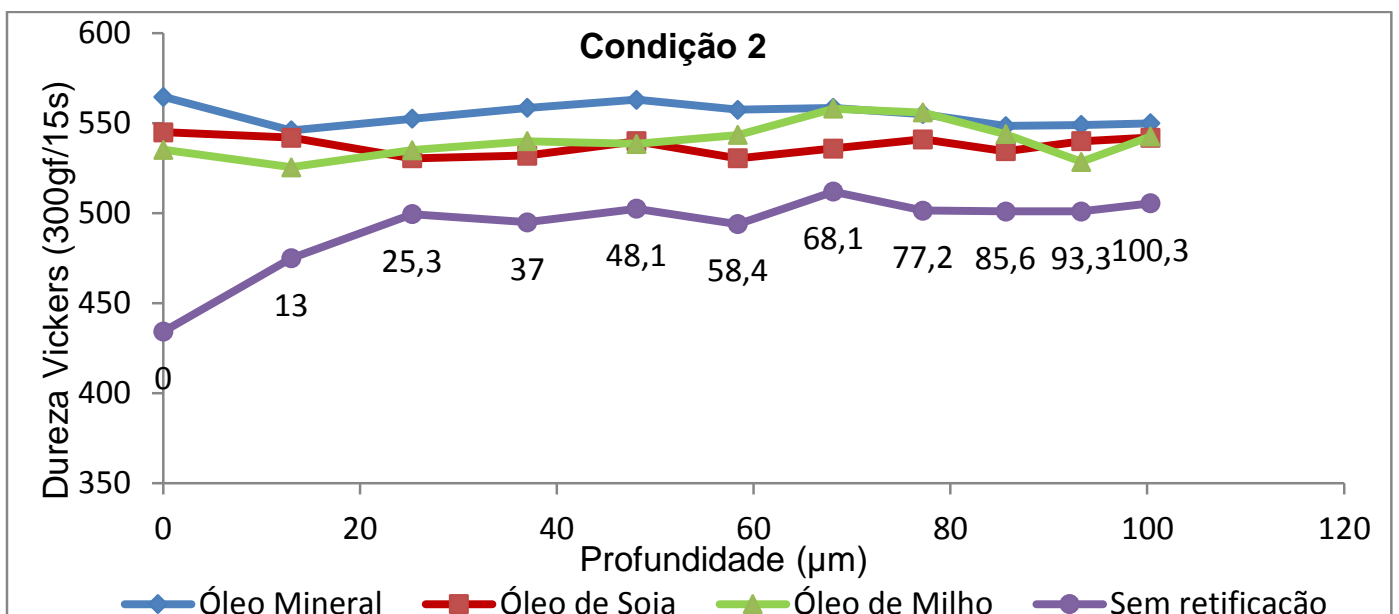

Figura 15. Valores de microdureza obtidos na condição de usinagem 2. $\left(V_{f}=0,8 \mathrm{~mm} / \mathrm{min}\right.$ e $\left.t_{s}=10 \mathrm{~s}\right)$.

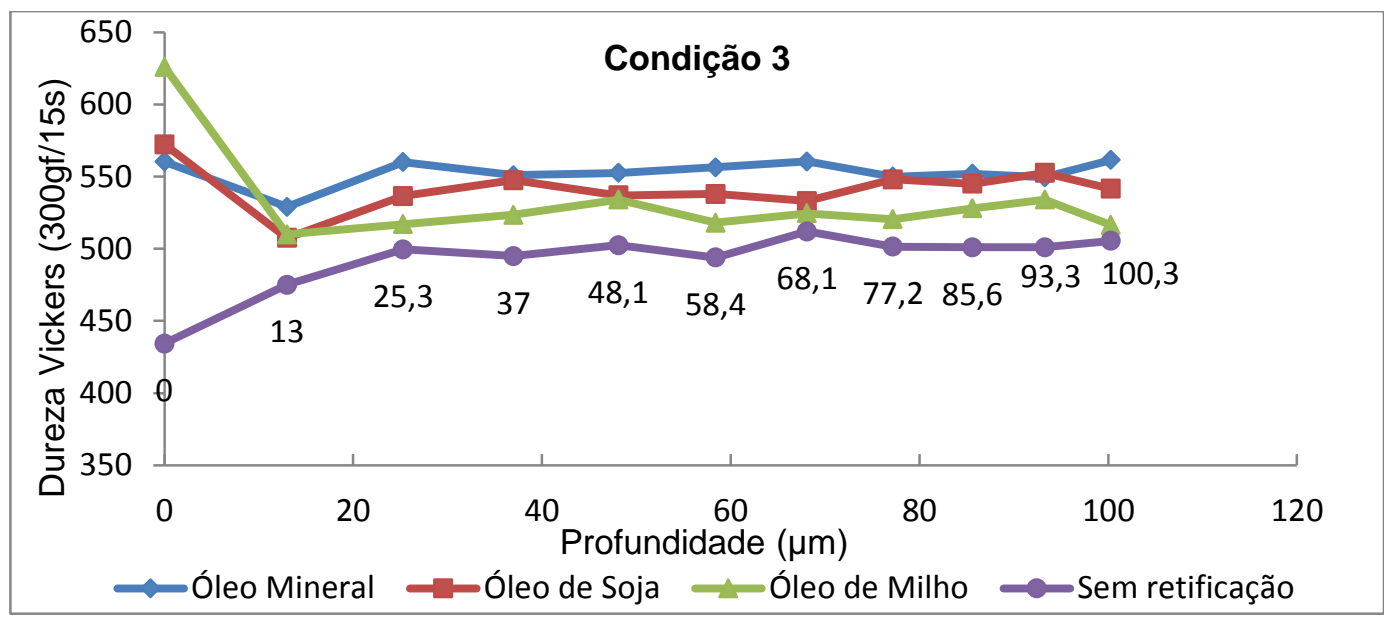

Figura 16. Valores de microdureza obtidos na condição de usinagem 3. $\left(V_{f}=1,2 \mathrm{~mm} / \mathrm{min}\right.$ e ts $\left.=10 \mathrm{~s}\right)$.

Analisando os gráficos observa-se uma considerável variação de microdureza entre a superfície (profundidade 0) e a sub-superfície das amostras considerando os três fluidos de corte e as três condições de usinagem. A superfície, em todas as amostras, apresentou maiores valores de microdureza. Na amostra não retificada,

* Contribuição técnica ao 69 Congresso Anual da ABM - Internacional e ao 14ํㅡㄹ ENEMET - Encontro Nacional de Estudantes de Engenharia Metalúrgica, de Materiais e de Minas,21 a 25 de julho de 2014, São Paulo, SP, Brasil. 


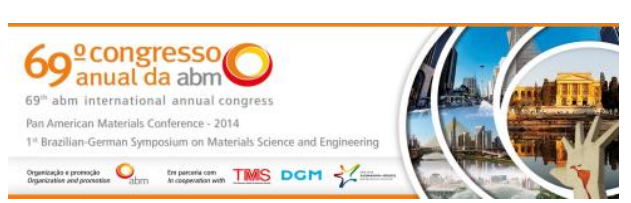

porém, o comportamento observado foi contrário. A superfície apresentou valores de dureza inferiores aos da sub-superfície. Estes dados são condizentes com a análise microestrutural, que mostrou maior quantidade de martensita (o que leva a maiores valores de microdureza) nas amostras retificadas em comparação com a amostra não retificada. Na subsuperfície, as variações de microdureza foram relativamente pequenas.

\section{CONCLUSÃo}

A partir dos resultados obtidos conclui-se que a retificação com óleo mineral e óleo de soja proporciona valores de rugosidade próximos. Na retificação com óleo de milho, embora tenha apresentado valores elevados de rugosidade, proporcionou menor variação dos valores.

Quanto ao desgaste diametral do rebolo, os resultados foram também consideravelmente semelhantes na retificação com óleo mineral e óleo de soja.

Os resultados de microscopia eletrônica de varredura e microdureza foram condizentes e demonstraram que não ocorreram alterações microestruturais diferentes das já esperadas no processo de retificação quanto ao emprego dos fluidos de corte.

De maneira geral observa-se, com os resultados obtidos, que o óleo de soja apresenta elevado potencial como fluido de corte no processo de retificação uma vez que as variáveis analisadas (rugosidade, desgaste do rebolo, microestrutura e microdureza) foram compatíveis com os resultados do óleo mineral, fluido de corte amplamente utilizado na indústria.

\section{Agradecimentos}

Ao CNPq pela bolsa de Produtividade em Pesquisa e à FAPEMIG pelo auxílio referente ao Programa Institucional de Bolsas de Iniciação Científica, Edital 84/12. Ao CEFET-MG e ao Departamento de Engenharia de Materiais DEMAT.

\section{REFERÊNCIAS}

1 Malkin S. Grinding technology: theory and applications of machining with abrasives. 1 ed. Chichester: Ellis Horwood Limited; 1989. p.275.

2 Alves MCS, Bianchi EC, Aguiar PR. Influência da velocidade de avanço do rebolo nos danos de aços endurecidos retificados. Revista Matéria. 2008;13(4):636-642.

3 Oliveira JFG, Alves SM. Adequação dos processos de usinagem utilizando produção mais limpa como estratégia de gestão ambiental. Produção. 2007;17(1):129-138.

4 Reddy NSK, Rao PV. Experimental investigation study the effect of solid lubricantions on cutting forces and surface quality in end milling. International Journal of Machine Tools and Manufacture. 2006;46:189-198.

5 Oliveira JFG, Alves SM. Novos fluidos de corte adequados ao desempenho mecânico da retificadora e ao meio ambiente. Máquinas e Metais. 2006;Jan.:28-43.

6 Japanese Industrial Standards. JIS B 0601: Surface roughness.

7 American Society for Testing Materials. ASTME-384-99: Standard test for knop and vickers hardness of materials. West Conshohocken.

\footnotetext{
* Contribuição técnica ao $69^{\circ}$ Congresso Anual da ABM - Internacional e ao 14ํㅡㄹ ENEMET - Encontro Nacional de Estudantes de Engenharia Metalúrgica, de Materiais e de Minas,21 a 25 de julho de 2014, São Paulo, SP, Brasil.
} 